University of Wollongong

Research Online

Australian Institute for Innovative Materials -

Papers

Australian Institute for Innovative Materials

$1-1-2012$

\title{
K0.25Mn2O4 nanofiber microclusters as high power cathode materials for rechargeable lithium batteries
}

\author{
Chaofeng Zhang \\ University of Wollongong, czhang@uow.edu.au \\ Chuanqi Feng \\ Hubei University, China, cfeng@uow.edu.au \\ Peng Zhang \\ University of Wollongong \\ Zaiping Guo \\ University of Wollongong, zguo@uow.edu.au \\ Zhixin Chen \\ University of Wollongong, zchen@uow.edu.au
}

See next page for additional authors

Follow this and additional works at: https://ro.uow.edu.au/aiimpapers

Part of the Engineering Commons, and the Physical Sciences and Mathematics Commons

Research Online is the open access institutional repository for the University of Wollongong. For further information contact the UOW Library: research-pubs@uow.edu.au 


\title{
K0.25Mn204 nanofiber microclusters as high power cathode materials for rechargeable lithium batteries
}

\author{
Abstract \\ $\mathrm{K}_{0.25} \mathrm{Mn}_{2} \mathrm{O}_{4}$ microclusters assembled from single-crystalline nanofibers were synthesized via a \\ hydrothermal process at different temperatures. The possibility of using these materials as cathode \\ material for lithium ion batteries was studied for the first time. The charge/discharge results showed that \\ the $\mathrm{K}_{0.25} \mathrm{Mn}_{2} \mathrm{O}_{4}$ nanofiber microclusters synthesized at 120 degrees $\mathrm{C}$ exhibit excellent lithium storage \\ properties, with a high reversible capability (360 $\mathrm{mA} \mathrm{h} \mathrm{g}^{-1}$ at current density of $\left.100 \mathrm{~mA} \mathrm{~g}^{-1}\right)$ and stable \\ lithium-ion insertion/de-insertion reversibility. The charge/discharge mechanism in lithium ion batteries \\ was studied and proposed for the first time. During the charge process, $\mathrm{K}^{+}$was extracted from the \\ electrode, which made active vacated sites suitable for lithium ion intercalation and was beneficial for \\ increasing capacity.

\section{Keywords} \\ $25 \mathrm{mn} 204, \mathrm{k0}$, rechargeable, materials, cathode, power, high, batteries, microclusters, lithium, nanofiber \\ Disciplines \\ Engineering | Physical Sciences and Mathematics

\section{Publication Details} \\ Zhang, C, Feng, C, Zhang, P, Guo, Z, Chen, Z, Li, S \& Liu, HK (2012), K0.25Mn2O4 nanofiber microclusters \\ as high power cathode materials for rechargeable lithium batteries, RSC Advances, 2(4), pp. 1643-1649.

\section{Authors} \\ Chaofeng Zhang, Chuanqi Feng, Peng Zhang, Zaiping Guo, Zhixin Chen, Sean Li, and Hua-Kun Liu
}




\title{
$\mathrm{K}_{0.25} \mathrm{Mn}_{2} \mathrm{O}_{4}$ Nanofiber Microclusters as High Power Cathode Materials for Rechargeable Lithium Batteries
}

\author{
Chaofeng Zhang, ${ }^{a, b}$ Chuanqi Feng, ${ }^{c}$ Peng Zhang, ${ }^{a, b}$ Zaiping Guo, ${ }^{a, b}$ Zhixin Chen, ${ }^{b}$ \\ Sean $\mathrm{Li}^{d}$ and Huakun Liu ${ }^{\mathrm{a}}$
}

$\mathrm{K}_{0.25} \mathrm{Mn}_{2} \mathrm{O}_{4}$ microclusters assembled from single-crystalline nanofibers were synthesized via a hydrothermal process at different temperatures. The possibility of using these materials as cathode material for lithium ion batteries was studied for the first time. The charge/discharge results showed that the $\mathrm{K}_{0.25} \mathrm{Mn}_{2} \mathrm{O}_{4}$ nanofiber microclusters synthesized at $120^{\circ} \mathrm{C}$ exhibit excellent lithium storage properties, with a high reversible capability $\left(360 \mathrm{~mA} \mathrm{~h} \mathrm{~g}^{-1}\right.$ at current density of $\left.100 \mathrm{~mA} \mathrm{~g}^{-1}\right)$ and stable lithium-ion insertion/de-insertion 10 reversibility. The charge/discharge mechanism in lithium ion batteries was studied and proposed for the first time. During the charge process, $\mathrm{K}^{+}$was extracted from the electrode, which made active vacated sites suitable for lithium ion intercalation and was beneficial for increasing capacity.

\section{Introduction}

During the past few decades, one of the most attractive research 15 areas in both science and technology has been rechargeable lithium-based batteries, which are currently regarded as the power source of choice for portable devices and potential power sources for electric vehicles (EVs), hybrid electric vehicles (HEVs), etc. ${ }^{1-3}$ It is consumer demand that drives research efforts 20 for batteries with high energy density, fast recharging times, and excellent cycling stability. Great efforts have been made to develop competitive electrode materials for rechargeable lithium batteries with superior electrochemical performance. ${ }^{4,} 5$ Compared with the development of anode materials, developing 25 cathode materials with good electrochemical performance is even more crucial to meet the requirements of the rapidly increasing portable electronics market, as well as potential applications in EVs and HEVs. ${ }^{6,7}$ Lithium transition metal oxide, with the formula of $\mathrm{LiMO}_{2}(\mathrm{M}: \mathrm{Mn}, \mathrm{Co}$, and $\mathrm{Ni}),{ }^{8-15}$ and transition metal 30 phosphate materials $\left(\mathrm{LiFePO}_{4}\right)^{16,17}$ have been widely investigated and reported as cathode materials, especially commercial $\mathrm{LiCoO}_{2}$. These cathode materials have limited power density (W/kg) compared to double layer capacitors and pseudocapacitors, and therefore cannot completely meet the practical requirements for ${ }_{35}$ EVs and HEVs, which need both high energy density and high power density. So far, developing cathode materials with low cost, environmental friendliness, better safety, and high energy and power densities, as well as excellent cycling stability, is still a challenge. ${ }^{1}$

40 In recent years, manganese-based materials $\left(\mathrm{MnO}_{2}, \mathrm{Li}_{\mathrm{x}} \mathrm{Mn}_{2} \mathrm{O}_{4}\right.$, etc.) have received increasing attention due to their high abundance, non-toxicity, and environmental friendliness. ${ }^{18-21}$ Manganese oxides are very well known for their suitable properties as cathode materials in Li-based batteries, especially $\alpha$ ${ }_{45} \mathrm{MnO}_{2}{ }^{22-25}$ Alkaline or alkaline-earth ions hosted in cathode materials can enhance their electrochemical performance, probably because they stabilize the structures of the cathode materials during the lithium insertion/extraction, as well as increasing the interlayer space, thus increasing the ion diffusion 50 rate in materials such as $\mathrm{NaV}_{3} \mathrm{O}_{8}, \mathrm{LiMnO}_{4}, \mathrm{Mg}\left(\mathrm{V}_{3} \mathrm{O}_{8}\right)_{2}$, etc. ${ }^{26-30}$ On the other hand, nanosized materials and porous materials have larger surface-to-volume ratios that enhance the contact between the active material grains and the electrolyte, and shorten the ion diffusion pathways. ${ }^{31}$ It could be deduced that a cathode material 55 with nanosize porous structure and alkaline or alkaline-earth element doping would show improved electrochemical performance.

As a member of the manganese-based materials family, cryptomelane-type $\mathrm{K}_{0.25} \mathrm{Mn}_{2} \mathrm{O}_{4}$ materials have been prepared by ${ }_{60}$ different approaches, which can result in different morphology, and different particle sizes and particle size distributions. ${ }^{32-36}$ Single-crystalline $\mathrm{K}_{0.25} \mathrm{Mn}_{2} \mathrm{O}_{4}$ could be suitable as a cathode material for lithium ion batteries because its potassium ions can not only maintain the structure, but also increase the ion diffusion ${ }_{65} \mathrm{rate}^{26-30}$ However, to the best of our knowledge, no investigations have been conducted on single-crystalline $\mathrm{K}_{0.25} \mathrm{Mn}_{2} \mathrm{O}_{4}$ as a cathode material for lithium ion batteries so far. Herein, we report the electrochemical properties of $\mathrm{K}_{0.25} \mathrm{Mn}_{2} \mathrm{O}_{4}$ microclusters for the first time and propose its reaction mechanism as cathode 70 material in lithium ion batteries. The $\mathrm{K}_{0.25} \mathrm{Mn}_{2} \mathrm{O}_{4}$ microclusters, assembled from single-crystalline nanofibers with diameters of 10-20 nanometers, were prepared by a facile hydrothermal technique. The $\mathrm{K}_{0.25} \mathrm{Mn}_{2} \mathrm{O}_{4}$ prepared at $120^{\circ} \mathrm{C}$, with a high Brunauer-Emmett-Teller (BET) surface area of $84.2 \mathrm{~m}^{2} \mathrm{~g}^{-1}$, 75 delivered a specific discharge capacity of $223 \mathrm{~mA} \mathrm{~h} \mathrm{~g}^{-1}$ at a current density of $300 \mathrm{~mA} \mathrm{~g}^{-1}$ and exhibited excellent cycling stability, indicating that the $\mathrm{K}_{0.25} \mathrm{Mn}_{2} \mathrm{O}_{4}$ single-crystalline nanofiber microclusters could be a very promising candidate material for rechargeable lithium batteries.

\section{${ }_{80}$ Experimental}

\section{Sample preparation}

All chemicals, including manganese (II) acetate tetrahydrate $\left(\mathrm{MnAc}_{2} \cdot 4 \mathrm{H}_{2} \mathrm{O}\right) 99 \%$, oxone monopersulfate compound (triple salt $\left.2 \mathrm{KHSO}_{5} \cdot \mathrm{KHSO}_{4} \cdot \mathrm{K}_{2} \mathrm{SO}_{4}\right)$, and potassium nitrate $\left(\mathrm{KNO}_{3}\right)$, were 85 bought from Sigma-Aldrich Co. Ltd. All reagents were used without any further purification. Nanofiber microclusters of cryptomelane-type manganese oxide $\left(\mathrm{K}_{0.25} \mathrm{Mn}_{2} \mathrm{O}_{4}\right)$ were prepared via a template-free, one-step hydrothermal method. ${ }^{36}$ Five representative samples, designated as KMO-80, KMO-100, ${ }_{90} \mathrm{KMO}-110$, KMO-120, and $\mathrm{KMO}-130$ were synthesized at different hydrothermal temperatures of $80,100,110,120$, and $130{ }^{\circ} \mathrm{C}$, respectively. The synthesis procedure employed oxone 
and potassium nitrate as the oxidant, while manganese (II) acetate tetrahydrate was selected to build the oxide network. In one typical synthesis, $0.2 \mathrm{~g}$ of manganese (II) acetate tetrahydrate and $0.165 \mathrm{~g}$ of potassium nitrate were dissolved in $5 \mathrm{~mL}$ de-ionized 5 water, and the resulting solution was labeled as solution A. Solution B was prepared by dissolving $1.5 \mathrm{~g}$ of oxone in $10 \mathrm{~mL}$ of double de-ionized water. After the mixing of the two solutions, the resultant mixture was then transferred to an autoclave and kept in an oven at $80{ }^{\circ} \mathrm{C}$ for 20 hours. After the autoclave was 10 cooled down, the product was separated and washed by centrifugation with de-ionized water several times, and then dried at $60{ }^{\circ} \mathrm{C}$ under vacuum conditions.

\section{Sample characterization}

The microstructures of the as-prepared samples were 15 characterized by X-ray diffraction (XRD; GBC MMA diffractometer) with $\mathrm{Cu} \mathrm{K} \alpha$ radiation and a graphite monochromator at a scanning rate of $2^{\circ} \mathrm{min}^{-1}$ in the range of 10 $70^{\circ}$. Raman analysis was performed with a Jobin Yvon HR800 Raman spectrometer. X-ray photoelectron spectroscopy (XPS) 20 experiments were carried out on a VG Scientific ESCALAB 2201XL instrument using $\mathrm{Al} \mathrm{K} \alpha \mathrm{X}$-ray radiation. The morphologies of the samples were investigated by field emission scanning electron microscopy (FE-SEM; JEOL JSM-7500FA). The Brunauer-Emmett-Teller (BET) surface areas of the 25 synthesized materials were measured by a NOVA 1000 high speed gas sorption analyser (Quantachrome Corporation, USA). Before BET measurements, the samples were degassed in vacuum at $100{ }^{\circ} \mathrm{C}$ for at least $12 \mathrm{~h}$. Transmission electron microscope (TEM) images were collected on a JEOL 2011200

${ }_{30} \mathrm{kV}$ instrument, with a JEOL Energy Dispersive X-ray Spectroscopy (EDS) detector and a JEOL EDS software analysis system. The working electrodes were prepared by mixing $75 \mathrm{wt} \%$ as-prepared $\mathrm{K}_{0.25} \mathrm{Mn}_{2} \mathrm{O}_{4}$ active materials with $15 \mathrm{wt} \%$ carbon black and $10 \mathrm{wt} \%$ polyvinylidene difluoride (PVdF, Sigma${ }_{35}$ Aldrich) binder in N-methyl-2-pyrrolidinone (NMP, SigmaAldrich, anhydrous, $99.5 \%$ ) to form a homogeneous slurry, which was then uniformly pasted onto aluminum foil. The prepared working electrodes were dried in a vacuum oven at $100{ }^{\circ} \mathrm{C}$ over 12 hours and were then ready for assembling into a 40 test cell after pressing. Electrochemical cells (CR2032 coin type) using the $\mathrm{K}_{0.25} \mathrm{Mn}_{2} \mathrm{O}_{4}$ as working electrode, $\mathrm{Li}$ foil as the counter electrode, a microporous polypropylene film as the separator, and $1 \mathrm{M} \mathrm{LiPF}_{6}$ in a 1:1 (v/v) mixture of ethylene carbonate (EC) and diethyl carbonate (DEC) as the electrolyte were assembled in an 45 Ar-filled glove box $\left(\mathrm{H}_{2} \mathrm{O}, \mathrm{O}_{2}<0.1 \mathrm{ppm}\right.$, Mbraun, Unilab, USA). The cells were galvanostatically charged and discharged over a voltage range of $1.5-4.2 \mathrm{~V}$ versus $\mathrm{Li} / \mathrm{Li}^{+}$at different constant current densities, based on the weight of the active materials, on a Land CT2001A cycler. Cyclic voltammetry was conducted using ${ }_{50}$ a three-electrode system with $\mathrm{Li}$ foil as counter electrode and reference electrode on a CHI660C electrochemical workstation.

\section{Results and Discussions}

The $\mathrm{K}_{0.25} \mathrm{Mn}_{2} \mathrm{O}_{4}$ is composed of an octahedral molecular sieve (OMS), which is built from double chains of edge-sharing $\mathrm{MnO}_{6}$ 55 octahedra, forming $(2 \times 2)+(1 \times 1)$ tunnel structures, with potassium ions situated in the large $(2 \times 2)$ tunnels, as shown in
Fig. 1. The structural features of these $\mathrm{K}_{0.25} \mathrm{Mn}_{2} \mathrm{O}_{4}$ samples were confirmed by X-ray diffraction (XRD) patterns, as shown in Fig. 2 , with all peaks labeled, which demonstrates that all the 60 reflections of these samples are in good agreement with the standard pattern of the pure tetragonal cryptomelane phase (JCPDS card file 29-1020). No other phases or impurities were detected, even though the microstructures were synthesized at a slightly lower temperature $\left(80,100\right.$, and $\left.110{ }^{\circ} \mathrm{C}\right)$ than the 65 temperature used in the previous study $\left(120^{\circ} \mathrm{C}\right) .{ }^{36}$ As can be observed, the KMO- 80 sample exhibits weaker and broader XRD peaks compared to samples synthesized at higher temperatures. The XRD peaks become sharper and more intense with increasing synthesis temperature, suggesting enhancement of the 70 crystallinity. ${ }^{29}$ However, the XRD peak of KMO-130 is weaker than that of KMO-120, probably because the higher temperature has destroyed the morphological structure of the material. The chemical compositions of the as-prepared products were analyzed by using inductively coupled plasma/atomic emission 75 spectroscopy (ICP/AES). These samples give similar molar ratios of K:Mn, which are between 0.121 and 0.126 . The ratios of $\mathrm{K}: \mathrm{Mn}$ are very close to the ratio for cryptomelane with a half occupancy of the tunnel sides, $\mathrm{K}_{0.125} \mathrm{MnO}_{2}{ }^{36}$

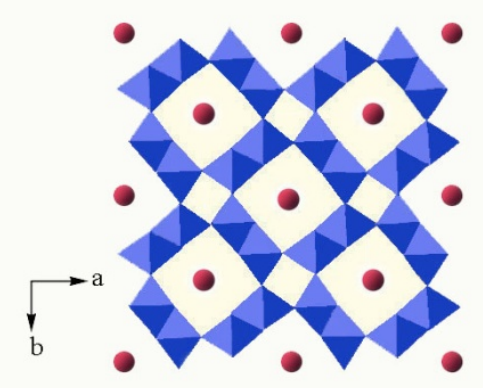

Fig. 1 Structure of cryptomelane-type manganese oxide $\mathrm{K}_{0.25} \mathrm{Mn}_{2} \mathrm{O}_{4}$, with $\mathrm{K}$ and $\mathrm{MnO}_{6}$ octahedra shown as red balls and blue polyhedra, respectively.

85

Scanning electron microscope (SEM) images (Fig. 3) show that the four samples (KMO-80, KMO-100, KMO-110, and KMO-120) have uniform morphology over large domains. The KMO-80 and KMO-100 samples exhibit uniform microspherical 90 morphology (Fig. 3a and 3b). When the synthesis temperature was increased to $110^{\circ} \mathrm{C}$, circular or oval holes (Fig. 3c) began to appear in the uniform spherical microstructures. On further increasing the hydrothermal temperature to $120^{\circ} \mathrm{C}$, the circular or oval holes were enlarged and hollow microstructures formed. Fig. ${ }_{95} \mathrm{~S} 1$ (Supporting Information) shows high resolution SEM (HRSEM) images of these four samples. Compared to the images of KMO-80 (Fig. S1a), KMO-100 (Fig. S1b), and KMO-110 (Fig. S1c), the nanofibers in KMO-120 (Fig. S1d) are more straight, which is probably due to their higher crystallinity. The uniform 100 hollow microstructures, with diameters of less than $5 \mu \mathrm{m}$, are assembled from a complex arrangement of long nanoscale fibers 
with diameters from $10-20 \mathrm{~nm}$ (inset of Fig. S1d and Fig.3d). Diverse microspheres, with non-uniform structures were found in the images of KMO-130 (Fig. S2).

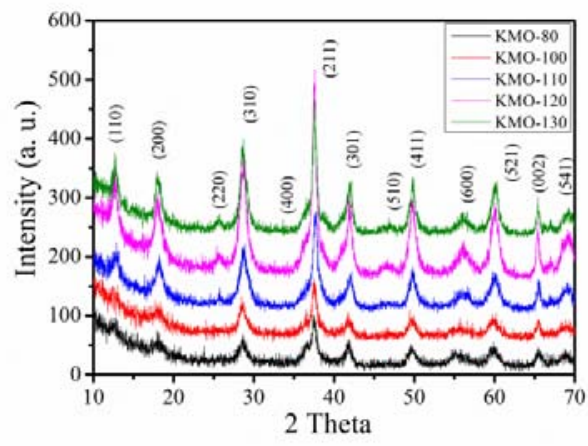

Fig. 2 Powder XRD patterns of different $\mathrm{K}_{0.25} \mathrm{Mn}_{2} \mathrm{O}_{4}$ nanomaterials.

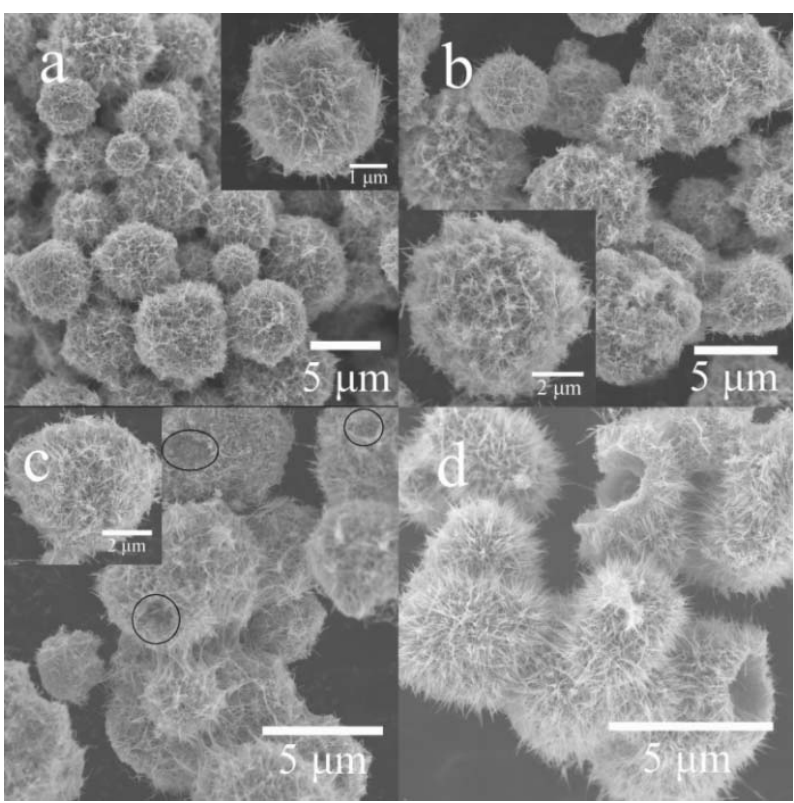

Fig. 3 SEM images of different $\mathrm{K}_{0.25} \mathrm{Mn}_{2} \mathrm{O}_{4}$ nanomaterials: (a) KMO-80; 10 (b) KMO-100; (c) KMO-110; (d) KMO-120. The insets of (a), (b), and (c) show enlargements of representive structures, respectively.

A transmission electron microscope (TEM) image (Fig. 4a) of the as-prepared KMO-120 sample shows an individual sphere 15 which is composed of numerous fibers. Fig. $4 \mathrm{~b}$ and c contain high resolution TEM (HRTEM) images, showing that the diameters of these nanofibers are in the range of 10-20 nm, The inset of Fig. $4 \mathrm{c}$ shows the lattice fringes of a selected nanofiber with an interplanar distance of $0.49 \mathrm{~nm}$, which is in good agreement with 20 the $d$-spacing of (200) planes of the cryptomelane structure (JCPDS 29-1020). Fig. 4d shows the corresponding selected area electron diffraction (SAED) pattern from the nanofiber, which is recorded from the $\left[\begin{array}{lll}0 & 1 & 1\end{array}\right]$ zone axis. The white spots verify the single crystalline nature of the $\mathrm{K}_{0.25} \mathrm{Mn}_{2} \mathrm{O}_{4}$ nanofibers and show 25 that the crystal grows along [211]*. These single crystal nanofibers facilitate the transportation of $\mathrm{Li}$ ions.

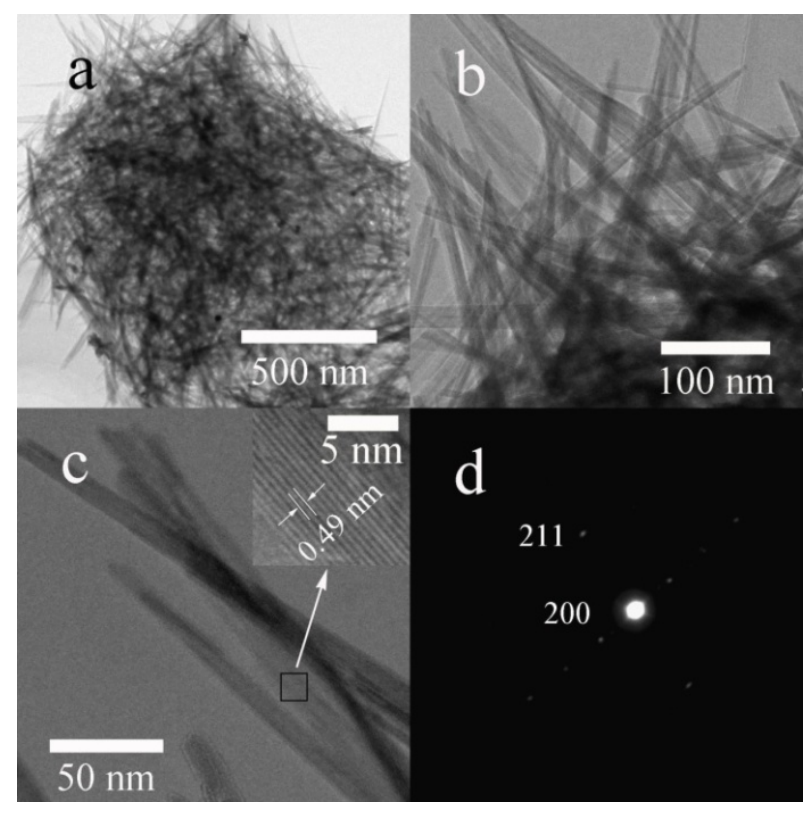

30

Fig. 4 (a, b) TEM images of KMO-120; (c) HRTEM image of the nanoscale fibers; the inset shows the lattice fringe spacing for the area indicated by the small rectangle; (d) the corresponding selected area electron diffraction pattern.

35

The electrochemical performance of the as-prepared $\mathrm{K}_{0.25} \mathrm{Mn}_{2} \mathrm{O}_{4}$ microclusters as cathode materials for lithium ion batteries was investigated. Fig. 5a presents the first cycle charge-discharge profiles for the different $\mathrm{K}_{0.25} \mathrm{Mn}_{2} \mathrm{O}_{4}$ electrodes at $100 \mathrm{~mA} \mathrm{~g}^{-1}$ at ${ }_{40}$ room temperature. KMO- 80 delivers the lowest discharge capacity of $246 \mathrm{~mA} \mathrm{~h} \mathrm{~g}^{-1}$, whereas KMO-120 exhibits the best performance for $\mathrm{Li}$ insertion, with a capacity of $360 \mathrm{~mA} \mathrm{~h} \mathrm{~g}^{-1}$. To evaluate the cycling performance of different samples, electrochemical tests up to 100 cycles were performed at a 45 current density of $100 \mathrm{~mA} \mathrm{~g}^{-1}$ (Fig. 5b). After 100 cycles, the discharge capacities of KMO-100, KMO-110, and KMO-120 are 99,125 , and $160 \mathrm{~mA} \mathrm{~h} \mathrm{~g}^{-1}$, which are about $40 \%, 60 \%$, and $80 \%$ of their second discharge capacities, respectively. The capacity of KMO- 80 drops rapidly and is only $126 \mathrm{~mA} \mathrm{~h} \mathrm{~g}^{-1}$ after 51 cycles, 50 which is only $60 \%$ of its second discharge capacity. The capacity of KMO-130 drops quickly and is about $134 \mathrm{~mA} \mathrm{~h} \mathrm{~g}^{-1}$ after 67 cycles, which is far less than that of KMO-120. The high temperature has destroyed the uniform structure of the microclusters, which results in the agglomeration of nanofibers. 55 Therefore, the contact area between electrolyte and active materials is decreased. Generally, the performance of electrode materials is very strongly influenced by the morphology, purity, crystalline phase, and porosity of the structure. ${ }^{37}$ Zhou et al. prepared single-crystalline nanowires of $\mathrm{LiMn}_{2} \mathrm{O}_{4}$, which showed 60 capacity of around $100 \mathrm{~mA} \mathrm{~h} \mathrm{~g}^{-1}$ after 100 cycles at a $5 \mathrm{~A} \mathrm{~g}^{-1}$ rate. ${ }^{38}$ Zhao et al. synthesized single-crystalline $\mathrm{LiMn}_{2} \mathrm{O}_{4}$ nanotubes using $\beta-\mathrm{MnO}_{2}$ nanotubes as a self-sacrifice template, presenting superior high-rate capability and cycling stability (with $70 \%$ of its initial capacity retained after 1500 cycles at the 5 ${ }_{65} \mathrm{C}$ rate). ${ }^{8}$ As one can see from Fig. 5a and b, KMO-120 exhibits the best electrochemical performance and cycling stability, probably due to two reasons: the single crystalline nature of its nanofibers (shown in Fig. 4d), ${ }^{29,37,38}$ and its larger surface area, 
which is $84.2 \mathrm{~m}^{2} \mathrm{~g}^{-1}\left(71.7,68.2\right.$, and $67.6 \mathrm{~m}^{2} \mathrm{~g}^{-1}$ for KMO-110, $\mathrm{KMO}-100$, and KMO-80, respectively), as estimated by the BET method. For the above-mentioned reasons, all of the following work is based on KMO-120 unless otherwise noted.
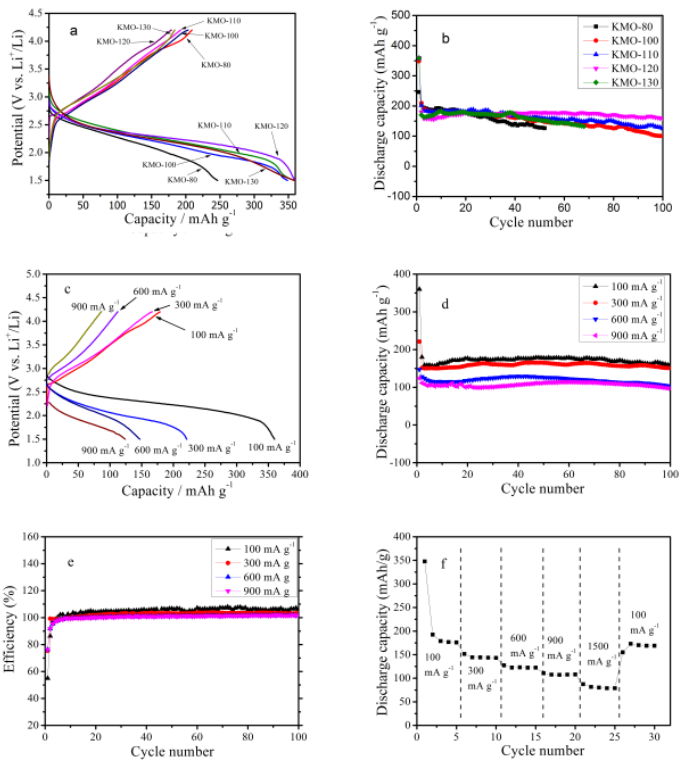

Fig. 5 (a) First cycle discharge-charge profiles and (b) cycling performance for KMO-80, KMO-100, KMO-110, KMO-120, and KMO10130 at current density of $100 \mathrm{~mA} \mathrm{~g}^{-1}$. Electrochemical measurements on the $\mathrm{K}_{0.25} \mathrm{Mn}_{2} \mathrm{O}_{4}$ electrode (KMO-120): (c) first cycle charge-discharge profiles at various current densities for $\mathrm{K}_{0.25} \mathrm{Mn}_{2} \mathrm{O}_{4}$ electrode; (d) cycling performance of the $\mathrm{K}_{0.25} \mathrm{Mn}_{2} \mathrm{O}_{4}$ electrode at various current densities between 1.5 and $4.2 \mathrm{~V}$ vs. $\mathrm{Li}^{\prime} / \mathrm{Li}^{+}$; (e) coulombic efficiency of the $15 \mathrm{~K}_{0.25} \mathrm{Mn}_{2} \mathrm{O}_{4}$ electrode at various current densities between 1.5 and $4.2 \mathrm{~V}$ vs. $\mathrm{Li}^{2} / \mathrm{Li}^{+}$; (f) rate capability of the $\mathrm{K}_{0.25} \mathrm{Mn}_{2} \mathrm{O}_{4}$ electrode at various current densities between 1.5 and $4.2 \mathrm{~V}$ vs. $\mathrm{Li} / \mathrm{Li}^{+}$.

20 The results of typical cyclic voltammetry (CV) measurements on KMO-120 (assigned as $\mathrm{K}_{0.25} \mathrm{Mn}_{2} \mathrm{O}_{4}$ ) are displayed in Fig. S3a There is a strong cathodic peak at about $2.22 \mathrm{~V}$ vs. $\mathrm{Li} / \mathrm{Li}^{+}$during the first cycle of the CV scan, and the peak shifts to higher potential in the following cycles. Similar effects have been 25 observed previously. ${ }^{39-41}$ The reason for such a phenomenon is not exactly clear; however, it can be conjectured that some sort of local restructuring or 'activation' takes place in the material during the initial lithium intercalation. The peak in the cathodic sweep is ascribed to the lithium insertion process in the ${ }_{30} \mathrm{~K}_{0.25} \mathrm{Mn}_{2} \mathrm{O}_{4}$ electrode. One wide peak at about $3.0 \mathrm{~V}$ vs. $\mathrm{Li} / \mathrm{Li}^{+}$ appeared in the anodic sweep, indicating the behavior of lithium ions during extraction from the host electrode material. Therefore, the possible electrochemical reaction mechanism of lithium ions with $\mathrm{K}_{0.25} \mathrm{Mn}_{2} \mathrm{O}_{4}$ in lithium ion batteries can be tentatively 35 expressed in the following Equation $1: 29$

$\mathrm{K}_{0.25} \mathrm{Mn}_{2} \mathrm{O}_{4}+\mathrm{xLi}+\mathrm{xe}^{-} \leftrightarrow \mathrm{Li}_{\mathrm{x}} \mathrm{K}_{0.25} \mathrm{Mn}_{2} \mathrm{O}_{4}$

Fig. $5 \mathrm{c}$ shows the charge-discharge voltage profiles for the first cycle of the $\mathrm{K}_{0.25} \mathrm{Mn}_{2} \mathrm{O}_{4}$ electrode, which were collected at various current densities from 100 to $900 \mathrm{~mA} \mathrm{~g}^{-1}$. The discharge 40 capacities of the $\mathrm{K}_{0.25} \mathrm{Mn}_{2} \mathrm{O}_{4}$ cathode at 100,300 , 600, and 900 $\mathrm{mA} \mathrm{g}^{-1}$ are $360,221,147$, and $124 \mathrm{~mA} \mathrm{~h} \mathrm{~g}^{-1}$, respectively. The capacities and the discharge potentials decrease as the current density increases, due to the internal resistance and polarization. The cycling performance of the sample was investigated up to ${ }_{45} 100$ cycles at different current densities from 100 to $900 \mathrm{~mA} \mathrm{~g}^{-1}$ (Fig. 5d). After 100 discharge-charge cycles, the capacities of the sample cycled at $100,300,600$, and $900 \mathrm{~mA} \mathrm{~g}^{-1}$ were measured to be $160,150,102$, and $96 \mathrm{~mA} \mathrm{~h} \mathrm{~g}^{-1}$, respectively. The relevant coulombic efficiencies (Fig. 5e) of the $\mathrm{K}_{0.25} \mathrm{Mn}_{2} \mathrm{O}_{4}$ electrodes at 50 different current densities remain around $100 \%$ after several cycles, indicating the good reversibility. In order to investigate possible application in high power density devices, the rate capability of the $\mathrm{K}_{0.25} \mathrm{Mn}_{2} \mathrm{O}_{4}$ nanomaterial electrode was studied (Fig. 5f). The discharge capacities at 100, 300, 600, and $900 \mathrm{~mA}$ ${ }_{55} \mathrm{~g}^{-1}$ are approximately $175,151,121$, and $107 \mathrm{~mA} \mathrm{~h} \mathrm{~g}$, respectively, and the capacity is still $80 \mathrm{~mA} \mathrm{~h} \mathrm{~g}$ even at the $1500 \mathrm{~mA} \mathrm{~g}^{-1}$ rate. When the current density is reduced to $100 \mathrm{~mA}$ $\mathrm{h} \mathrm{g}^{-1}$ after the rate performance testing, the $\mathrm{K}_{0.25} \mathrm{Mn}_{2} \mathrm{O}_{4}$ cell can provide the formerly measured value $\left(169 \mathrm{~mA} \mathrm{~h} \mathrm{~g} \mathrm{~g}^{-1}\right)$ again, 60 indicating its good reversibility and high rate capability.

Fig. S3b shows the number of $\mathrm{Li}$ ions inserted per formula unit during the first charge-discharge measurement at various current densities from 100 to $900 \mathrm{~mA} \mathrm{~g}^{-1}$. At the current density of 100 $\mathrm{mA} \mathrm{g} \mathrm{g}^{-1}$, approximately $2.4 \mathrm{Li}^{+}$ions per formula unit were 65 intercalated into the host material, while only $1.2 \mathrm{Li}^{+}$ions per formula unit can be de-intercalated from the material during charging. When the current density was increased to 300,600 , and $900 \mathrm{~mA} \mathrm{~g}^{-1}$, the numbers of $\mathrm{Li}^{+}$ions intercalated were around $1.5,1.0$, and 0.8 per formula unit, while the numbers of $\mathrm{Li}^{+}$ions 70 extracted were about $1.1,0.7$, and 0.6 per formula unit, respectively.

As can be seen from Fig. $5 \mathrm{~d}$, the capacities of the $\mathrm{K}_{0.25} \mathrm{Mn}_{2} \mathrm{O}_{4}$ electrodes kept rising at the initial stage, except for the first few cycles, which is similar to the phenomenon that occurs in ${ }_{75} \mathrm{NaV}_{6} \mathrm{O}_{15}$ electrode. ${ }^{29}$ It is assumed that the potassium ions in the tunnels were de-intercalated during the charging process in the initial stage and then more lithium ions could be intercalated into the $\mathrm{K}_{0.25} \mathrm{Mn}_{2} \mathrm{O}_{4}$ electrode in the following discharge process. Thus, the amount of $\mathrm{K}^{+}$in the $\mathrm{K}_{0.25} \mathrm{Mn}_{2} \mathrm{O}_{4}$ electrode before and ${ }_{0}$ after the charge-discharge process is significant for investigating the behavior of $\mathrm{K}^{+}$in the charge-discharge procedure.

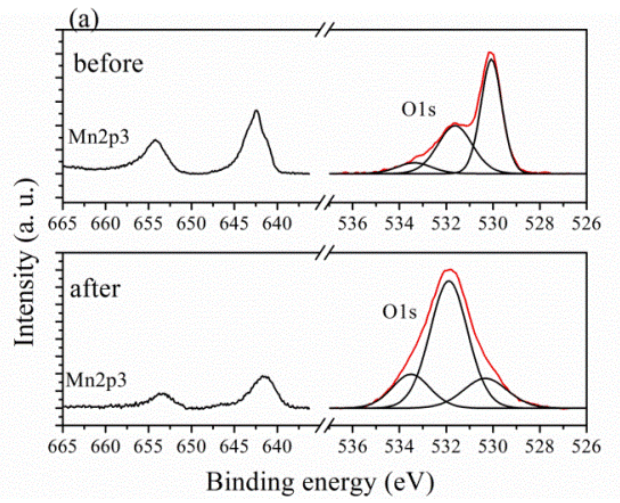




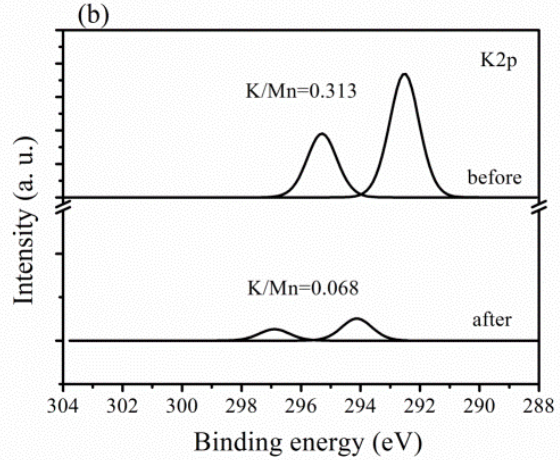

Fig. 6 XPS spectra of the (a) Mn2p and O1s, and (b) the K2p regions for the $\mathrm{K}_{0.25} \mathrm{Mn}_{2} \mathrm{O}_{4}$ electrode before and after 100 cycles of charge-discharge 5 at a current density of $100 \mathrm{~mA} \mathrm{~g}^{-1}$.

To determine the change in the number of $\mathrm{K}^{+}$ions and the reversible insertion and extraction behavior of lithium ions in the $\mathrm{K}_{0.25} \mathrm{Mn}_{2} \mathrm{O}_{4}$ nanofibers, X-ray photoelectron spectroscopy (XPS) 10 was carried out to investigate the surface concentrations of the corresponding elements and the chemical states of the species in the $\mathrm{K}_{0.25} \mathrm{Mn}_{2} \mathrm{O}_{4}$. Fig. 6a shows the $\mathrm{O} 1 \mathrm{~s}$ and $\mathrm{Mn} 2 \mathrm{p}$ spectra for the $\mathrm{K}_{0.25} \mathrm{Mn}_{2} \mathrm{O}_{4}$ electrode before and after charge-discharge cycling. There are three distinctive binding energies in the O1s spectrum 15 of fresh $\mathrm{K}_{0.25} \mathrm{Mn}_{2} \mathrm{O}_{4}$ electrode: $531.08,531.58$, and $533.38 \mathrm{eV}$. The binding energy at $531.08 \mathrm{eV}$ is assigned to the lattice oxygen $\left(\mathrm{O}^{2-}\right)$; the medium binding energy $(531.58 \mathrm{eV})$ is ascribed to the surface absorbed oxygen $\left(\mathrm{O}_{2}^{-}, \mathrm{O}^{-}\right), \mathrm{OH}$ groups, or oxygen vacancies; and the binding energy of $533.38 \mathrm{eV}$ is probably due 20 to the absorbed molecular water from air during sample transportation. ${ }^{42-47}$ As indicated in Fig. 6a, a freshly prepared electrode typically shows two Mn2p peaks, with binding energies of $642.38 \mathrm{eV}$ for $\mathrm{Mn} 2 \mathrm{p} 3 / 2$ and $654.18 \mathrm{eV}$ for Mn2p1/2, and with a spin-energy separation of $11.8 \mathrm{eV}$, indicating the presence of 25 tetravalent $\mathrm{Mn}$ and trivalent $\mathrm{Mn}^{46-48}$ After 100 charge-discharge cycles at $100 \mathrm{~mA} \mathrm{~g}^{-1}$, the $\mathrm{K}_{0.25} \mathrm{Mn}_{2} \mathrm{O}_{4}$ cell was disassembled and washed in ethylene carbonate (EC) in an Ar-filled glove box before being investigated by XPS. As one can see from Fig. 6a, the XPS spectra of Mn2p show that the binding energies of the ${ }_{30} \mathrm{~K}_{0.25} \mathrm{Mn}_{2} \mathrm{O}_{4}$ electrode after 100 charge-discharge cycles are $641.68 \mathrm{eV}$ for $\mathrm{Mn} 2 \mathrm{p} 3 / 2$ and $653.38 \mathrm{eV}$ for $\mathrm{Mn} 2 \mathrm{p} 1 / 2$, which are shifted to lower binding energies in comparison with the fresh electrode. The shift towards lower binding energies suggests that the electron densities of $\mathrm{Mn}$ atoms have increased, which 35 indicates an increase in low-valence Mn species. ${ }^{49-51}$ This is consistent with the decrease in intensity of the oxygen low binding energy peak $\left(531.08 \mathrm{eV}\right.$, corresponding to $\left.\mathrm{O}^{2-}\right)$ and the increase of the oxygen medium binding energy peak $(531.58 \mathrm{eV}$, corresponding to $\mathrm{O}^{-}$or $\mathrm{O}_{2}^{-}$) to keep the valence state balanced.

${ }_{40}$ Fig. $6 \mathrm{~b}$ shows the core level K2p peak recorded from the fresh $\mathrm{K}_{0.25} \mathrm{Mn}_{2} \mathrm{O}_{4}$ electrode and the same electrode after electrochemical measurements, as well as the relative ratio of $\mathrm{K}: \mathrm{Mn}$. The amount of potassium element is reduced, and the ratio of $\mathrm{K}: \mathrm{Mn}$ was reduced from the initial value of 0.313 to 0.068 45 after the electrochemical measurements, indicating that approximately $80 \%$ of the $\mathrm{K}^{+}$ions were extracted during the charge process. For the freshly prepared electrode, the main sharp line at $292.5 \mathrm{eV}$ for $\mathrm{K} 2 \mathrm{p}_{3 / 2}$, accompanied by the satellite line at $295.3 \mathrm{eV}$ for $\mathrm{K} 2 \mathrm{p}_{1 / 2}$, is attributed to the $\mathrm{K}-\mathrm{O}$ group. ${ }^{52-54}$ After 100 50 cycles, the binding energies of K are shifted to 293.9 and 296.3 $\mathrm{eV}$. The positive binding energy shift indicates a decrease in the electron density of potassium due to the extraction of potassium from $\mathrm{K}_{0.25} \mathrm{Mn}_{2} \mathrm{O}_{4}$, in which there is a stronger interaction between potassium and lattice oxygen. ${ }^{52-57}$ Since the potassium was 55 extracted from the $\mathrm{K}_{0.25} \mathrm{Mn}_{2} \mathrm{O}_{4}$ host materials, Equation 1, which describes the reversible insertion/extraction behavior of lithium, should be amended as:

$\mathrm{K}_{0.25} \mathrm{Mn}_{2} \mathrm{O}_{4}+\mathrm{xLi}+\mathrm{xe}^{-} \rightarrow \mathrm{Li}_{\mathrm{x}} \mathrm{K}_{0.25} \mathrm{Mn}_{2} \mathrm{O}_{4}$ (First discharge process)

${ }_{60} \mathrm{Li}_{\mathrm{x}} \mathrm{K}_{0.25} \mathrm{Mn}_{2} \mathrm{O}_{4}-\mathrm{yLi}-\mathrm{mK}-(\mathrm{y}+\mathrm{m}) \mathrm{e}^{-} \rightarrow \mathrm{Li}_{\mathrm{x}-\mathrm{y}} \mathrm{K}_{0.25-\mathrm{m}} \mathrm{Mn}_{2} \mathrm{O}_{4}$

$(\mathrm{y}<\mathrm{x}, \mathrm{m}<0.25) \quad$ (First charge process)

$\mathrm{Li}_{\mathrm{x}-\mathrm{y}} \mathrm{K}_{0.25-\mathrm{m}} \mathrm{Mn}_{2} \mathrm{O}_{4}(\mathrm{y}<\mathrm{x}, \mathrm{m}<0.25)+\mathrm{zLi}+\mathrm{ze}^{-} \leftrightarrow$

$\mathrm{Li}_{\mathrm{x}-\mathrm{y}+\mathrm{z}} \mathrm{K}_{0.25-\mathrm{m}} \mathrm{Mn}_{2} \mathrm{O}_{4} \quad(\mathrm{y}<\mathrm{x}, \mathrm{m}<0.25)$

(Reversible electrochemical reaction)

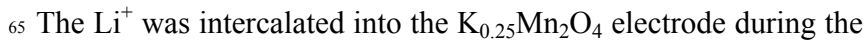
first discharge, and then a certain number of $\mathrm{Li}^{+}$ions, together with some $\mathrm{K}^{+}$ions, were de-intercalated from the cathode in the first charge process. Since $\mathrm{K}^{+}$was extracted from the electrode, some vacated active sites appeared and became available for $\mathrm{Li}^{+}$ 70 in the following discharge process, resulting in the increasing capacity. In addition, there may be chemical ion exchange between $\mathrm{K}$ and $\mathrm{Li}$ due to the presence of excess $\mathrm{Li}$ in the electrolyte. The intercalated $\mathrm{Li}$ and $\mathrm{K}$ already there in the pristine form were electrochemically removed upon charge, which is 75 supported by the increase in capacity (Figure 5d) and the coulombic efficiencies above $100 \%$, as shown in Figure $5 \mathrm{e}$ (calculated from the charge capacity/discharge capacity). After 100 cycles of charge-discharge, there are a certain amount of $\mathrm{Li}^{+}$ ions in the electrode, which is consistent with the Raman results 80 (Fig. S4). However, the irreversible $\mathrm{Li}^{+}$in the $\mathrm{Li}_{\mathrm{x}} \mathrm{K}_{0.25} \mathrm{Mn}_{2} \mathrm{O}_{4}$ reduces the trend towards increasing $\mathrm{Li}^{+}$per formula unit in the following cycles, as is shown in Fig. 5d (where the capacity slightly increases in the initial stage, but exhibits capacity dropping in the first several cycles). With stable charge-discharge 85 cycling at the current density of $100 \mathrm{~mA} \mathrm{~g} \mathrm{~g}^{-1}$, the amount of lithium which could be electrochemically intercalated into the $\mathrm{K}_{0.25} \mathrm{Mn}_{2} \mathrm{O}_{4}$ electrode was about $1.1 \mathrm{Li}^{+}$per formula unit. Even when cycled at the current density of $900 \mathrm{~mA} \mathrm{~g} \mathrm{~g}^{-1}$, there was around $0.66 \mathrm{Li}^{+}$per formula unit inserted into the host ${ }_{90} \mathrm{~K}_{0.25} \mathrm{Mn}_{2} \mathrm{O}_{4}$ electrode after 100 cycles, corresponding to $96 \mathrm{~mA} \mathrm{~h}$ $\mathrm{g}^{-1}$.

\section{Conclusions}

The electrochemical performance of cryptomelane-type $\mathrm{K}_{0.25} \mathrm{Mn}_{2} \mathrm{O}_{4}$ nanofiber microclusters is reported for the first time. ${ }_{95}$ Cryptomelane-type $\mathrm{K}_{0.25} \mathrm{Mn}_{2} \mathrm{O}_{4}$ microclusters assembled from nanofibers show excellent electrochemical performance. At current density of $100 \mathrm{~mA} \mathrm{~g}{ }^{-1}$, the $\mathrm{K}_{0.25} \mathrm{Mn}_{2} \mathrm{O}_{4}$ electrode exhibited a reversible discharge capacity as high as $160 \mathrm{~mA} \mathrm{~h} \mathrm{~g}^{-1}$ for up to 100 cycles. Even when measured at high current 
densities of 300,600 , and $900 \mathrm{~mA} \mathrm{~g}^{-1}$, it was able to deliver high discharge capacities (around 150, 102, and $96 \mathrm{~mA} \mathrm{~h} \mathrm{~g}^{-1}$, respectively) after 100 cycles of charge-discharge. The high rate capability and excellent cycling performance of the $\mathrm{K}_{0.25} \mathrm{Mn}_{2} \mathrm{O}_{4}$ 5 electrode can be attributed to its unique nanostructures, singlecrystalline nature, and the presence of $\mathrm{K}^{+}$, which helps to stabilize the structures and favor lithium ion diffusion. During the charge process, $\mathrm{K}^{+}$was extracted from the structure, which made active vacated sites suitable for lithium ion intercalation. Considering 10 the excellent rate capability, environmental friendliness, and facile fabrication method, $\mathrm{K}_{0.25} \mathrm{Mn}_{2} \mathrm{O}_{4}$ microclusters assembled from single-crystalline nanofibers could be a potential cathode material for lithium rechargeable batteries.

\section{Acknowledgements}

15 Financial support provided by the Australian Research Counci (ARC) through an ARC Discovery project (DP1094261) is gratefully acknowledged. The authors would like to thank Mr. Guodong Du, Dr. Shulei Chou, and Dr. Jun Liu at the University of Wollongong for their assistance in using laboratory equipment 20 or valuable remarks.

\section{Notes and references}

${ }^{a}$ Institute for Superconducting \& Electronic Materials,

University of Wollongong, NSW 2522, Australia

Email: zquo@uow.edu.au; Fax: 61242215731

${ }_{25}{ }^{b}$ School of Mechanical, Materials \& Mechatronics Engineering,

University of Wollongong, NSW 2522, Australia

${ }^{c}$ College of Chemistry \& Chemical Engineering,

Hubei University, Wuhan 430062, China

${ }^{d}$ School of Materials Science and Engineering,

30 The University of New South Wales, NSW 2052, Australia

1. M. Armand and J. M. Tarascon, Nature, 2008, 451, 652.

2. K. S. Kang, Y. S. Meng, J. Breger, C. P. Grey and G. Ceder, Science, 35 2006, 311, 977

3. M. S. Whittingham, Chem. Rev., 2004, 104, 4271.

4. G. Derrien, J. Hassoun, S. Panero and B. Scrosati, Adv. Mater., 2007, 19, 2336.

5. Y. G. Wang, H. Q. Li and Y. Y. Xia, Adv. Mater., 2006, 18, 2619.

40 6. J. K. Kim and A. Manthiram, Nature, 1997, 390, 265.

7. H. S. Zhou, D. L. Li, M. Hibino and I. Honma, Angew. Chem. Int Ed., 2005, 44, 797.

8. Y. L. Ding, J. A. Xie, G. S. Cao, T. J. Zhu, H. M. Yu and X. B. Zhao, Adv. Funct. Mater., 2011, 21, 348.

45 9. J. Y. Luo, H. M. Xiong and Y. Y. Xia, J. Phys. Chem. C, 2008, 112, 12051.

10. M. Okubo, E. Hosono, J. Kim, M. Enomoto, N. Kojima, T. Kudo, H. S. Zhou and I. Honma, J. Am. Chem. Soc., 2007, 129, 7444.

11. V. Subramanian, C. L. Chen, H. S. Chou and G. T. K. Fey, J. Mater. $50 \quad$ Chem., 2001, 11, 3348.

12. K. Mukai, J. Sugiyama, Y. Ikedo, P. L. Russo, D. Andreica, A. Amato, K. Ariyoshi and T. Ohzuku, J. Power Sources, 2009, 189, 665.

13. W. S. Yoon, K. Y. Chung, J. McBreen, D. A. Fischer and X. Q.
14. D. W. Liu, Y. Y. Liu, A. Q. Pan, K. P. Nagle, G. T. Seidler, Y. H. Jeong and G. Z. Cao, J. Phys. Chem. C, 2011, 115, 4959.

15. L. Q. Mai, L. Xu, C. H. Han, X. Xu, Y. Z. Luo, S. Y. Zhao and Y. L. Zhao, Nano Lett., 2010, 10, 4750.

60 16. Y. G. Wang, Y. R. Wang, E. J. Hosono, K. X. Wang and H. S. Zhou, Angew. Chem. Int. Ed., 2008, 47, 7461.

17. A. Yamada, H. Koizumi, S. I. Nishimura, N. Sonoyama, R. Kanno, M. Yonemura, T. Nakamura and Y. Kobayashi, Nat. Mater., 2006, 5, 357.

65 18. F. Jiao, J. L. Bao, A. H. Hill and P. G. Bruce, Angew. Chem. Int. Ed., 2008, 47, 9711 .

19. F. Y. Cheng, J. Z. Zhao, W. Song, C. S. Li, H. Ma, J. Chen and P. W. Shen, Inorg. Chem., 2006, 45, 2038.

20. H. S. Fang, L. P. Li, Y. Yang, G. F. Yan and G. S. Li, J. Power Sources, 2008, 184, 494.

21. G. D. Du, J. Q. Wang, Z. P. Guo, Z. X. Chen and H. K. Liu, Mater. Lett., 2011, 65, 1319.

22. M. H. Rossouw, D. C. Liles, M. M. Thackeray, W. I. F. David and S. Hull, Mater. Res. Bull., 1992, 27, 221.

75 23. C. S. Johnson, D. W. Dees, M. F. Mansuetto, M. M. Thackeray, D. R. Vissers, D. Argyriou, C. K. Loong and L. Christensen, J. Power Sources, 1997, 68, 570.

24. P. Botkovitz, P. Deniard, M. Tournoux and R. Brec, J. Power Sources, 1993, 44, 657.

80 25. L. I. Hill, A. Verbaere and D. Guyomard, J. Power Sources, 2003, 119, 226

26. R. J. Chen and M. S. Whittingham, J. Electrochem. Soc., 1997, 144, L64.

27. D. Ahn, I. Yoo, Y. M. Koo, N. Shin, J. Kim and T. J. Shin, J. Mater. $85 \quad$ Chem., 2011, 21, 5282.

28. M. E. Spahr, P. Novak, W. Scheifele, O. Haas and R. Nesper, J. Electrochem. Soc., 1998, 145, 421.

29. H. M. Liu, Y. G. Wang, L. Li, K. X. Wang, E. Hosono and H. S. Zhou, J. Mater. Chem., 2009, 19, 7885.

90 30. G. Pistoia, M. Pasquali, G. Wang and L. Li, J. Electrochem. Soc., 1990, 137, 2365.

31. M. M. Rahman, J. Z. Wang, M. F. Hassan, S. L. Chou, Z. X. Chen and H. K. Liu, Energy Environ. Sci., 2011, 4, 952.

32. H. Huang, S. Sithambaram, C. H. Chen, C. K. Kithongo, L. P. Xu, A.

95 Iyer, H. F. Garces and S. L. Suib, Chem. Mater., 2010, 22, 3664.

33. B. X. Hu, C. H. Chen, S. J. Frueh, L. Jin, R. Joesten and S. L. Suib, J. Phys. Chem. C, 2010, 114, 9835.

34. N. N. Opembe, C. K. King'ondu, A. E. Espinal, C. H. Chen, E. K. 100 Nyutu, V. M. Crisostomo and S. L. Suib, J. Phys. Chem. C, 2010, 114, 14417.

35. T. Gao, M. Glerup, F. Krumeich, R. Nesper, H. Fjellvag and P. Norby, J. Phys. Chem. C, 2008, 112, 13134.

36. H. M. Galindo, Y. Carvajal, E. Njagi, R. A. Ristau and S. L. Suib, $105 \quad$ Langmuir, 2010, 26, 13677.

37. H. W. Lee, P. Muralidharan, R. Ruffo, C. M. Mari, Y. Cui and D. K. Kim, Nano Lett., 2010, 10, 3852.

38. E. Hosono, T. Kudo, I. Honma, H. Matsuda and H. S. Zhou, Nano Lett., 2009, 9, 1045.

110 39. A. Esmanski and G. A. Ozin, Adv. Funct. Mater., 2009, 19, 1999. 
40. M. Green, E. Fielder, B. Scrosati, M. Wachtler and J. Serra Moreno, Electrochemical and Solid State Letters, 2003, 6, A75.

41. C. K. Chan, H. L. Peng, G. Liu, K. McIlwrath, X. F. Zhang, R. A. Huggins and Y. Cui, Nature Nanotechnology, 2008, 3, 31.

${ }_{5}$ 42. L. Yu, G. Q. Diao, F. Ye, M. Sun, J. L. Zhou, Y. F. Li and Y. Liu, Catal. Lett., 2011, 141, 111.

43. V. P. Santos, M. F. R. Pereira, J. J. M. Orfao and J. L. Figueiredo, Applied Catalysis B-Environmental, 2010, 99, 353.

44. L. A. Sun, Q. Q. Cao, B. Q. Hu, J. H. Li, J. M. Hao, G. H. Jing and

10 X. F. Tang, Applied Catalysis a-General, 2011, 393, 323.

45. S. Kim, H. B. Pyo, S. H. Ko, C. S. Ah, A. Kim and W. J. Kim, Langmuir, 2010, 26, 7355.

46. X. J. Yang, J. Y. Han, Z. P. Du, H. Yuan, F. Jin and Y. X. Wu, Catal. Commun., 2010, 11, 643.

15 47. T. Gao, P. Norby, F. Krumeich, H. Okamoto, R. Nesper and H. Fjellvag, J. Phys. Chem. C, 2010, 114, 922.

48. X. F. Tang, Y. G. Li, J. L. Chen, Y. D. Xu and W. J. Shen, Microporous Mesoporous Mater., 2007, 103, 250.

49. R. R. Hu, C. F. Yan, L. Y. Xie, Y. Cheng and D. Z. Wang, Int. J.

$20 \quad$ Hydrogen Energy, 2011, 36, 64.

50. X. S. Liu, Z. N. Jin, J. Q. Lu, X. X. Wang and M. F. Luo, Chem. Eng. J., 2010, 162, 151.

51. J. C. Ge, L. H. Zhuo, F. Yang, B. Tang, L. Z. Wu and C. H. Tung, J. Phys. Chem. B, 2006, 110, 17854.

25 52. Y. Joseph, G. Ketteler, C. Kuhrs, W. Ranke, W. Weiss and R. Schlogl, PCCP, 2001, 3, 4141.

53. K. Jiratova, J. Mikulova, J. Klempa, T. Grygar, Z. Bastl and F. Kovanda, Applied Catalysis a-General, 2009, 361, 106.

54. L. Xue, C. B. Zhang, H. He and Y. Teraoka, Catal. Today, 2007, 126, 449.

55. A. Miyakoshi, A. Ueno and M. Ichikawa, Applied Catalysis aGeneral, 2001, 219, 249.

56. M. L. Xiang, D. B. Li, J. Zou, W. H. Li, Y. H. Sun and X. C. She, Journal of Natural Gas Chemistry, 2010, 19, 151.

35 57. A. Caballero, J. P. Espinos, A. Fernandez, L. Soriano and A. R. GonzalezElipe, Surf. Sci., 1996, 364, 253. 


\section{Supplementary:}

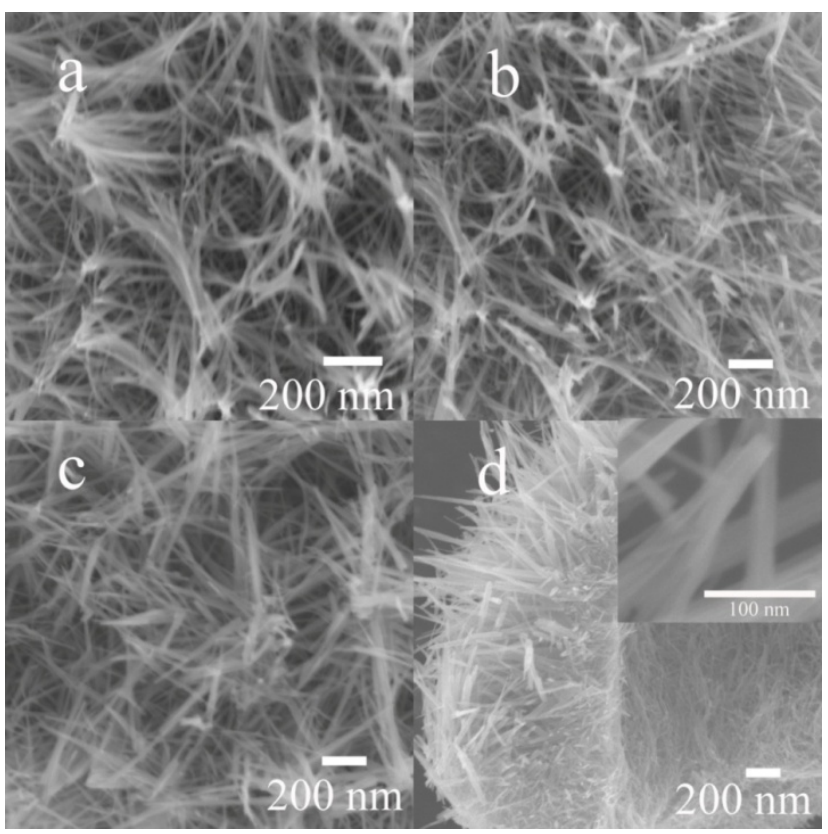

Fig. S1 HRSEM images of different $\mathrm{K}_{0.25} \mathrm{Mn}_{2} \mathrm{O}_{4}$ nanomaterials show nanofibers of (a) KMO-80; (b) KMO-100; (c) KMO-110; (d) KMO-120, with the inset showing still higher magnification.

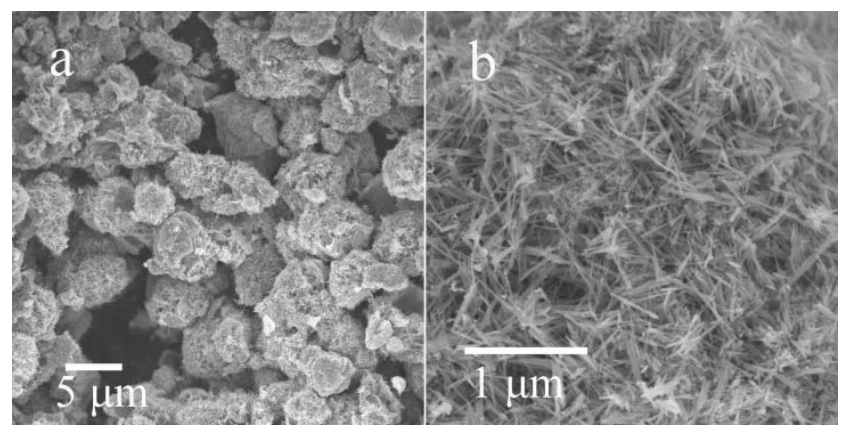

Fig. S2 SEM images of KMO-130 material. The KMO-130 was prepared by using the same hydrothermal method, with the reaction temperature of $130{ }^{\circ} \mathrm{C}$. The SEM image (Fig. S2a) of KMO-130 shows that the sample has diverse microspherical structures. The uniform microspherical morphologies which were found in KMO-80, KNO-100, KMO-110, and KMO-120 have disappeared. Fig S2b shows high resolution SEM (HRSEM) images of the sample.
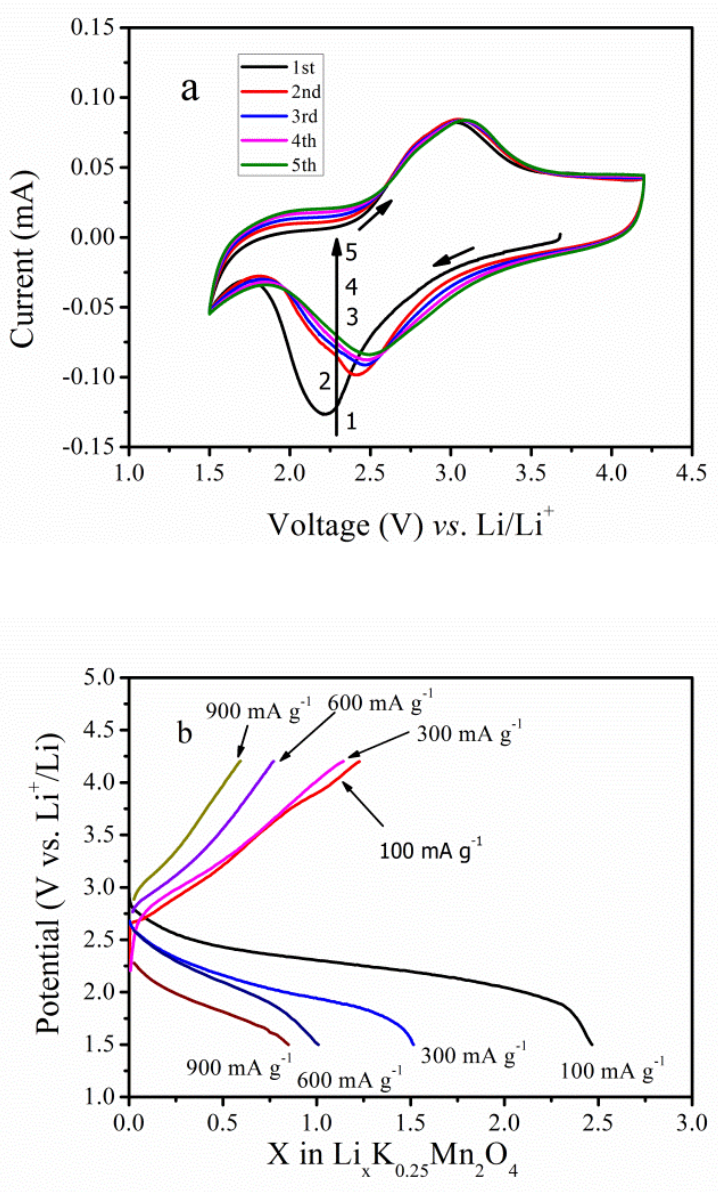

Fig. S3 Electrochemical measurements on the $\mathrm{K}_{0.25} \mathrm{Mn}_{2} \mathrm{O}_{4}$ electrode: (a) cyclic voltammograms for the first 5 cycles at scan rate of $0.1 \mathrm{mV} \mathrm{s}^{-1}$ (b) voltage vs. the amount of $\mathrm{Li}$ insertion in the $\mathrm{K}_{0.25} \mathrm{Mn}_{2} \mathrm{O}_{4}$ electrode at different current densities.

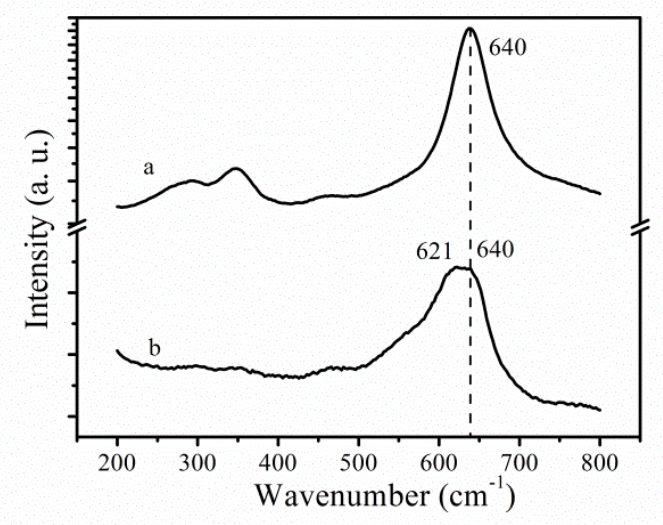

Fig. S4 Raman spectra of $\mathrm{K}_{0.25} \mathrm{Mn}_{2} \mathrm{O}_{4}$ nanofibers: a) before cycling, b) after 100 cycles at $100 \mathrm{~mA} \mathrm{~g}^{-1}$.

Raman spectroscopy was used to investigate vibrational information on the manganese-oxygen $\left(\mathrm{MnO}_{6}\right)$ octahedra in the $\mathrm{K}_{0.25} \mathrm{Mn}_{2} \mathrm{O}_{4}$. A representative Raman spectrum of fresh $\mathrm{K}_{0.25} \mathrm{Mn}_{2} \mathrm{O}_{4}$ electrode is shown in Fig. S4a. The sample shows a strong wide peak at approximately 640 
$\mathrm{cm}^{-1}$ and some weak shoulder bands around 291, 350, 395, and $460 \mathrm{~cm}^{-1}$. The high-frequency Raman band at $640 \mathrm{~cm}^{-1}$, which indicates well developed tetragonal structure with an interstitial space consisting of $(2 \times$ 2) tunnels, is assigned to the $A_{g}$ mode. ${ }^{1-3}$ The observed Raman frequencies in the 200-500 $\mathrm{cm}^{-1}$ range can be assigned to the $\mathrm{Mn}-\mathrm{O}$ stretching of $\mathrm{MnO}_{6}$ octahedra. ${ }^{4-7}$ A second Raman spectrum of this sample, collected after 100 charge-discharge cycles at $100 \mathrm{~mA} \mathrm{~g}^{-1}$, is shown in Fig. S4b. The Raman frequencies in the $200-500 \mathrm{~cm}^{-1}$ range remain unchanged, except for a slight shift. However, the strongest characteristic peak can be divided into two peaks, at 640 and $621 \mathrm{~cm}^{-1}$, indicating the elongation of the Mn-O bond, as evaluated from the results in the literature. ${ }^{7,8}$ The change has occurred because the surrounding environment of the Mn was changed by the presence of more Li ions.

1. Y. L. Ding, J. A. Xie, G. S. Cao, T. J. Zhu, H. M. Yu and X. B. Zhao, Adv. Funct. Mater., 2011, 21, 348.

2. S. J. Hwang, C. W. Kwon, J. Portier, G. Campet, H. S. Park, J. H. Choy, P. V. Huong, M. Yoshimura and M. Kakihana, J. Phys. Chem. B, 2002, 106, 4053.

3. T. Gao, M. Glerup, F. Krumeich, R. Nesper, H. Fjellvag and P. Norby, J. Phys. Chem. C, 2008, 112, 13134.

4. E. K. Nyutu, C. H. Chen, S. Sithambaram, V. M. B. Crisostomo and S. L. Suib, J. Phys. Chem. C, 2008, 112, 6786.

5. W. Y. Hernandez, M. A. Centeno, F. Romero-Sarria, S. Ivanova, M. Montes and J.

A. Odriozola, Catal. Today, 2010, 157, 160.

6. R. Baddour-Hadjean and J. P. Pereira-Ramos, Chem. Rev., 2010, 110, 1278.

7. L. A. Sun, Q. Q. Cao, B. Q. Hu, J. H. Li, J. M. Hao, G. H. Jing and X. F. Tang, Applied Catalysis a-General, 2011, 393, 323.

8. F. D. Hardcastle and I. E. Wachs, J. Phys. Chem., 1991, 95, 5031. 